\title{
The Social, Economic, and Public Health Consequences of Global Population Aging: Implications for Social Work Practice and Public Policy
}

\author{
Mitchell A. Kaplan \\ New York, New York \\ Marian M. Inguanzo \\ New York, New York
}

\begin{abstract}
Human populations around the world are growing older at the most astounding rate in the history of humanity. Advances in technology are enabling health care providers to deliver the latest innovations in treatment and prevention services to a broader spectrum of adult populations across the lifespan making longevity increasingly more commonplace rather than the exception to the rule in most of the industrialized world. This article provides an overview of the key social, economic, and public health costs and consequences that aging populations will exact upon international communities in the years ahead. It also examines the most significant social challenges that global societies will face regarding their ability to develop and implement social policies and service programs that can effectively respond to the changing needs of their adult citizens who are growing older.
\end{abstract}

Keywords: aging, population trends, social work, public policy

\section{Introduction}

The growth of aging populations around the world represents one of the crowning achievements of the latter half of the 20th century. Data from the United Nations Population Division indicates that the median age of humans in most western societies across the globe has risen by an average of 5 years over the last 2 decades. As international birth rates have declined and advances in medical science and technology have increased life expectancy, the proportional balance between younger and older adult populations in most developed countries has shifted dramatically. In 1950, only 5\% of the world's population was over the age of 65 . A little more than half a century later in 2006, that figure has almost doubled in size in most of the developed world. Historical analysis of demographic data collected by the United States Census Bureau since the beginning of the 20th century provides clear indications of the changes in the age distribution of the U.S. population. In 1900, the average lifespan for most Americans was 47.3 years; by 1997, that figure had increased to 76.5 years-an increase of 29.2 years in less than a century (Kramarow, Lentzner, Rooks, Weeks, \& Saydah, 1999). More recent data cited in a revised report published by the United Nations in 2010 projected that the world population of adults over the age of 65 is expected to reach 1.5 billion by the year 2050 (Heilig et al., 2011). Although some social scientists would argue that initial gains in U.S. life expectancy indicated by the census data do not reflect social differences in longevity associated with gender, race, social class, income, and education among the different demographic groups in American 
society. Most would agree that considerable progress has been made in this area over time. Data from demographic surveys conducted by researchers at the United Nations indicate that the proportional growth of the older adult population is expected to vary significantly from country to country in the years ahead (see Table 1).

Table 1. Percent of International Populations Over the Age of 60 in the Year 2000 and Predictions for the Year 2020

\begin{tabular}{lcc}
\hline Country & 2000 & 2020 \\
\hline Italy & 24 & 31 \\
Japan & 23 & 34 \\
Germany & 23 & 29 \\
Greece & 23 & 29 \\
Croatia & 22 & 26 \\
Spain & 21 & 27 \\
United Kingdom & 21 & 26 \\
France & 21 & 27 \\
Switzerland & 21 & 32 \\
Norway & 20 & 26 \\
Hungary & 20 & 26 \\
Slovenia & 19 & 29 \\
United States & 16 & 22 \\
\hline
\end{tabular}

Note. Source: Heilig et al. (2011).

For example, in Japan, which currently has one of the highest life expectancies in the industrialized world, the growth of the nation's older adult population is on the rise. Findings from population surveys conducted by the Japanese Ministry of Internal Affairs and Communications Bureau of Statistics (1996) provide clear indications that Japan's older adult population is increasing at a faster rate than that of most other countries in the western world, including the United States. According to 2014 estimates, $33 \%$ of the Japanese population is above the age of $60,26 \%$ is age 65 and older, and $13 \%$ is age 75 and older. People age 65 and older currently compose one fifth of Japan's total population (International Longevity Center Japan, n.d.). The number of Japanese people age 65 and older has quadrupled in the last 40 years, reaching 33 million in 2014 (Ministry of Internal Affairs and Communications Bureau of Statistics, 1996). Social scientists project that at the current rate of growth, $40 \%$ of Japan's population will be 65 and older by the year 2060 ("Japan Population to Shrink," 2012). Social factors that are contributing to the rapid growth of the aging population in Japan are low postwar fertility rates, improved nutrition, advances in medical technology that have reduced life-threatening disease, and improved living conditions brought about by peace and economic prosperity.

Like other countries that are currently experiencing the economic and social effects of a growing aging population, Japan has begun to take steps toward the development of a broad range of innovative socioeconomic and public health policies designed to keep their older citizens healthier, economically engaged in the labor force, and active in society. For example, to address the growing dependency needs of its aging population, the Japanese government introduced long-term care insurance into its health care system in 2000 (Marlow, 2017). The Japanese government has also introduced a series of economic policies to address the shrinking supply of younger workers in its labor force. These policies encourage the participation of women in the workforce and bring into 
consideration the raising of the mandatory retirement age beyond 65 to preserve the economic solvency of the country's pension system in future decades (Faiola, 2006).

Japan is not the only global nation that is witnessing rapid population aging, findings from research, conducted by the World Health Organization (WHO) in 2009, reveal that $15 \%$ of the total population of the nations of the European Union are currently age 65 and older. WHO research suggests that if current expansion trends continue, one-quarter of the population of nations in the European region will be over the age of 60 by midcentury. For example, in Spain and Italy, two nations with fastgrowing aging populations, WHO data estimates that older adults will account for more than one third of the national populations (U.S. Department of Health and Human Services, National Institute on Aging National Institutes of Health and WHO, 2011). The data also indicate that the number of persons over the age of 80 is also rising globally. In Western Europe, $4 \%$ of the population of France and Germany is already age 80 and older. Experts believe the number of individuals age 80 and above is expected to reach nine million globally in the next 10 to 15 years (Davies, 2004). Data from longitudinal research conducted by the European Office for National Statistics confirm that aging populations are rapidly expanding throughout Europe (Aziz, 2002). For example, population surveys in England and Wales reveal a substantial rise in mortality among individuals age 80 and older, indicating a significant increase in longevity in those countries (WHO, 2004).

Demographic data associated with the expansion of aging global populations cited in U.N. reports predict that the elderly will account for $13 \%$ of the total world population within the next 2 decades (United Nations, Department of Economic and Social Affairs, Population Division, 2007). Research suggests that the largest amount of impending growth of the older adult population is expected to take place in the developing world where scientists forecast a $140 \%$ increase in the number of persons over the age of 60 . The forecast data also predicts that developed nations will also experience a $51 \%$ increase in their older adult populations in the decades ahead (International Federation of Social Workers [IFSW], 2008). According to demographic statistics cited in a published report produced by the U.S. Department of Health and Human Services, National Institute on Aging, National Institutes of Health, and U.S. Department of State (2007), there are currently almost 500 million people in the world age 65 and older. Older adults currently compose $8 \%$ of the world's population. Social scientists estimate that if present demographic trends continue at the current rate of expansion, the global population of older adults will reach 1 billion by the year 2030 (U.S. Department of Health and Human Services, National Institute on Aging, National Institutes of Health, and U.S. Department of State, 2007).

Demographic shifts in global aging populations over the next 2 decades are slated to have substantial social, economic, and public health consequences for the social structure of international societies regarding their ability to meet the changing health care and supportive service needs of their citizens who are growing older. In industrialized nations like the United States, which experienced a significant fertility boom in the second half of the 20th century, millions of aging baby boomers are now starting to leave the labor force to enter retirement. The retirement of large numbers of individuals from the American labor force in the coming decades will place significant economic strains upon the sustainability of Social Security and pension systems, as well as Medicare and Medicaid, which have been the main sources of economic security and health insurance benefits for millions of older Americans for generations. Global population aging will put public institutions under considerable social and political pressure to reorganize their priorities and resources in ways that will enable them to develop and implement social, economic, and public health programs that can effectively keep older adults out of poverty and be able to address their changing health care needs. International concern over key socioeconomic and public health issues associated with the 
expansion of aging populations has reached the threshold of the political agenda of world leaders whose government agencies are working hard to come up with strategic policies and programs that can provide an adequate response to these critical emerging social challenges.

The international demographic statistics cited above will have a substantial impact on social work practice as it relates to the development of aging policy and service implementation in the years ahead. Population aging data from these surveys will be used to inform social work professionals and government agencies about the social service, economic, health care, and housing programs that they will need to develop to assist older adults to remain engaged and independent in their communities. The data will also be used to inform social work educators about the need to train more social work students in the field of geriatrics so that they will acquire the specialized skills and knowledge necessary to work with older adult populations around the world.

\section{Social and Public Health Challenges Associated With Global Population Aging}

The expansion of population aging will present significant social challenges to global nations in future decades that will need to be addressed by public policy makers as well as the scientific community. Scientific experts who have studied the effects of population aging on global societies argue that this phenomenon will have a major impact on the social structure of international communities. Experts predict that global aging will have significant effects on international patterns of economic growth and trade, social migration, the sustainability of family systems, the ability of states and communities to provide a stable income and social support services for their older citizens and the incidence and prevalence of patterns of chronic disease and disability.

Substantial evidence for these predictions is indicated in the findings of regional surveys conducted by national and international government monitoring agencies such as the United Nations, the United States Census Bureau, the Statistical Office of European Communities, and the National Institute on Aging over the last decade. The research has identified several basic trends that scientists believe will represent the most important social challenges to our aging societies in future decades, including the following:

- Persons over the age of 65 are expected to outnumber children under the age of 5 in most developed countries in the coming decades.

- As longevity spirals upward in developed nations, the population of persons age 85 and older who are considered the oldest elderly is expected to increase dramatically.

- Noncommunicable chronic illness associated with the aging process-such as arthritis, cardiovascular disease, stroke, macular degeneration, cancer, diabetes, and Alzheimer's disease-are expected to become the leading causes of death and disability among older adults in global societies.

- As population aging expands and international birth rates decline, global family structures are going to change significantly, leaving thousands of adults with fewer options for longterm care as they age.

- As human life spans continue to increase, and older adults spend more time outside the labor force, international patterns of work and retirement are going to shift. That will leave taxpayer-supported social insurance programs in most developed countries with the task of 
finding new ways to maintain the economic solvency of these systems in the wake of increasing demands for the distribution of retirement benefits.

Scientific experts and government policy makers across the world who have examined the emerging social, economic, and public health challenges associated with the accelerated pace of population aging see them as opportunities to bring about social reforms that will assist international communities in coping more effectively with these changes. While some international government administrations have begun to develop concrete long-term strategic plans that will help their societies deal with the social challenges associated with population aging, most have not. For example, in European nations, the present ratio of working-age adults to retirees is currently four to one; scientists predict that as global populations continue to age, this ratio will shrink to two to one by the year 2050. Also, many economic experts believe that population aging will cause the proportion of the gross national product devoted to funding social insurance programs that provide retirement benefits to older adults to more than double in many European nations.

One of the greatest challenges that global societies will face in the coming decades will be finding new strategies for dealing with the growing burden of the spread of noncommunicable chronic diseases in aging populations. Scientific evidence from two epidemiological studies entitled The Global Burden of Disease (WHO, 2008) and The economic implications of chronic illness and disability in Eastern Europe and the former Soviet Union (World Bank, 2008) predicts sharp increases in quality of life-impairing disabilities caused by chronic diseases associated with the aging process. The studies project that over the next decade and a half, loss of healthy years of life from age-related noncommunicable chronic disease will surpass that of all infectious diseases and accidents combined in every region of the developed and developing world. The studies further suggest that the social and economic costs of controlling the proliferation of various forms of noncommunicable chronic disease associated with population aging will be shared proportionally by high-, low-, and middle-income nations around the globe. Scientists estimate that $87 \%$ of the noncommunicable diseases being treated in persons over the age of 60 in these countries in the future will be a direct result of population aging.

\section{Socioeconomic Implications of Population Aging for Older Adults With Disabilities}

There is substantial evidence documented in the scientific literature that as people age, they become more susceptible to chronic illnesses that result in the acquisition of long-term physical and mental disabilities. Epidemiological research conducted by WHO (2008) indicates that $20 \%$ of the world's population over the age of 70 , and $50 \%$ over the age of 85 , have some form of age-related physical or mental disability that limits daily activities and compromises their independence (Chappell \& Cook, 2010). The data also show that the relationship between aging and disability is associated with socially stigmatized stereotypes of disabled individuals in many international societies. Social scientists who have studied aging with a disability around the world argue that process carries with it a host of social and economic implications for the individual and society. As adults with disabilities enter their older years and their social and economic supports begin to wane, they become more vulnerable to the onset of poverty. Research conducted by the World Bank, WHO, and the United Nations between 2003 and 2008 indicates strong links between impoverished social conditions, aging, and disability in many industrialized countries in the developed world. Despite the fact that economic growth has been relatively stable in these countries for several decades (World Bank, 2008). The findings also indicate that older adults with disabilities face a host of social barriers when 
they seek employment in most developed countries. Key among these are social discrimination and prejudice associated with their disability and advancing age, which keeps thousands of qualified workers out of the competitive labor market in many nations and forces them into poverty. The situation is particularly true for women with disabilities who, because of their child-bearing and parental caregiver responsibilities, spend considerably less time working. Reduced time in the labor force places older women at a serious disadvantage when it comes to the amount of income they will receive when they retire. Subsequently, because women have a much greater life expectancy than men in most developed societies, those with disabilities are more likely to face poverty when they lose a major portion of their retirement income through the death of a spouse or divorce.

\section{End-of-Life Care in an Aging World}

Trend data from epidemiological studies conducted by WHO (2004) indicate that as life expectancy continues to rise in many European countries and the United States greater numbers of men and women are expected to survive into advanced old age. This will have a significant impact on patterns of chronic disease and disability experienced at the end of life. As aging populations grow larger in the future, patterns of chronic disease during the last years of life will be changing. More people will be expected to die from prolonged chronic age-related illnesses such as heart disease, cerebrovascular disease, respiratory disease, and advanced cancer than from acute short-term illness (see Table 2).

Table 2. Predicted Causes of Death Among Older Adults in 2020 and Previous Ones in 1990

\begin{tabular}{lcc}
\hline Health Disorder & Predicted Ranking 2020 & Previous Ranking 1990 \\
\hline Heart disease & 1 & 1 \\
$\begin{array}{l}\text { Cerebrovascular disease } \\
\quad \text { (including stroke) }\end{array}$ & 2 & 2 \\
$\begin{array}{l}\text { Chronic obstructive pulmonary } \\
\quad \text { disease }\end{array}$ & 3 & 6 \\
Lower respiratory infections & & 3 \\
Lung, trachea \& bronchial & 4 & 10 \\
\hline
\end{tabular}

Note. Source: Murray and Lopez (1997).

Also, health care professionals recognize that as world populations continue to age, increasing numbers of older adults will be living with the physical and mental effects of several long-term chronic illnesses such arthritis, osteoporosis, and dementia for longer periods of time. International mortality data from research conducted by the United Nations and the Office of National Statistics (1999) in Britain reveal significant gender differences in longevity among men and women worldwide. The data suggest that because older women tend to outlive older men by an average of 6 years in most developed countries, they face a higher vulnerability to the onset of disability caused by one or more chronic health conditions as they age. Subsequently, this will mean that older adults of both genders will require some form of assisted care especially as they approach the end of life (WHO, 2004).

With this projection in mind, public policy experts working for international government agencies have started to recognize that they must come up with social policies and programs that can assist health professionals to manage the changing medical and supportive service needs of seriously ill older adult populations. Public policies they develop must be able to provide global health care 
systems with the social supports and economic resources necessary to meet the challenge of creating programs that can effectively respond to the service needs of the chronically ill elderly, especially those systems in developing nations where access to financial resources to fund such initiatives are scarce.

To address the complex challenges of providing end-of-life care to elderly populations with chronic illness, many countries around the world including the United States have introduced palliative care programs into their health care systems. In 2002, WHO defined palliative care as a strategic approach that improves the quality of life of patients and their families who are facing the problems associated with life-threatening illness. Through early identification and clinical assessment, health care professionals working in palliative care programs can provide patients facing the end of life with interventions that can effectively prevent and relieve their physical pain and emotional suffering as well as help families to cope with the psychological and spiritual issues that surround the loss of a loved one. The palliative care movement began in Britain as a result of the pioneering work of Dame Cicely Saunders, who was both a professional nurse and a physician and focused on providing patients entering the final stages of advanced illness with comfort care rather than a cure for their disease.

Initially set up to assist patients and families experiencing the trauma of advanced cancer, the services of palliative care programs have been extended in recent years to encompass a wide range of other life-threatening diseases that accompany the aging process. The primary goal of palliative care programs is to provide the best quality of life possible at the end of life for terminally ill patients and their families. Palliative care programs integrate psychological and spiritual aspects of patient care and offer a system of supportive services that are designed to help patients with advanced illness to live as actively as possible until death. The programs also offer an interdisciplinary system of service supports to families to help them cope with the patient's illness and provide bereavement counseling when necessary. Palliative care programs provide these supportive services to patients and their family members throughout the entire illness experience, not just at the moment of death. Health care professionals who are members of palliative care teams are aware that the end-of-life care needs of older adults are different and more complex than those of younger adults with serious illness for the following reasons:

- Older adults are commonly affected by multiple medical conditions that vary in severity.

- The cumulative effect of these combined medical conditions is usually more extreme than any one individual disease and typically leads to higher levels of impairment and a greater need for care.

- Older adults are at greater risk of adverse drug reactions and illness complications associated with the diagnosis and treatment of their medical conditions.

- Minor medical conditions may have a greater psychological impact on the mental health of older adults.

As an integral part of the palliative care team, social work professionals can work with terminally ill older adults and their families to provide specific services that help them to effectively cope with the physical and emotional traumas that accompany the onset of lifethreatening illnesses. Given their professional values and specialized clinical training, social workers can be strong advocates for patient self-determination and culturally appropriate care for older adults in palliative care settings. The National Association of Social Workers (2004) 
handbook Standards for Palliative and End of Life Care defines care at the end of life as a multidimensional assessment involving the implementation of concrete interventions by service providers that are designed to assist individuals and families to cope with the decision-making process that accompanies the end of life. Social workers know that no matter how it occurs, whether sudden or expected, the process of dying is always a unique experience that exacts a significant impact upon the individual, the family system, and the family legacy.

\section{The Social Worker's Role in Global Communities Experiencing the Effects of Population Aging}

As discussed earlier in this article, the accelerated pace of population aging presents many daunting challenges for international communities regarding their ability to meet the evolving needs of their adult citizens who are growing older. As demographic trends continue to shift and older adults compose a greater proportion of world populations, the far-reaching socioeconomic and political effects of these changes on individuals of all ages will be very significant. Drawing on the initial goals outlined in the Madrid International Plan of Action on Ageing (United Nations, Division for Social Policy and Development, 2002), a product of the Second World Assembly on Ageing held in Madrid, Spain, in 2002, the IFSW issued a revised policy statement on aging and older adults in 2008. The statement gives recognition to the fact that older adults make substantial contributions to society and their life experiences represent a tangible resource that is very beneficial to younger generations. The IFSW strongly believes that increased longevity, as evidenced by the worldwide expansion of older adult populations, will create new opportunities for individual and social development that will have unprecedented effects on the structural functioning of international communities. Global population trends will also have a substantial impact on social work professionals regarding their ability to organize international resources and advocate for the development of aging-friendly social policies that support the implementation of service programs and research projects that can help older adults to remain productively engaged and independent in their communities. Social work professionals are aware that to develop an adequate response to the multilevel social challenges posed by population aging, older adults need to be mobilized to become actively involved in the formation of the government policies, programs, research agendas, and supportive services that will have a direct impact on their lives. Social workers recognize that as older adult populations continue to grow larger globally, the potential for them to become an important social and political force for change will increase. They will take a more active role in influencing the implementation of public policies that promote healthy aging, independent living, and productive lifestyle choices in later life on a global scale. The IFSW believes that to effectively mobilize international older adult populations to political action on policy issues that directly affect their quality of life will require the development of a multifaceted approach to community intervention tailored to the cultural norms of the society in which the intervention takes place. Major components of such interventions will be the development of strategic methods of community organization, the establishment of collaborative partnerships with community-based organizations and the facilitation of community outreach and social advocacy campaigns used to inspire older adults toward greater self-determination, political participation, and empowerment in their communities.

The IFSW (2008) acknowledges that social service providers have an important obligation to encourage the promotion of social policy principles within international communities that serve to enhance the general health and well-being of older adults through the reduction of social and 
cultural barriers that limit their access to beneficial service programs. These guiding principles are as follows:

- Implementation of country-specific international human rights legislation and protective legal instruments that enhance the basic freedoms of older adults and reduce all forms of socioeconomic disparity and social discrimination that serve to limit their full participation in society

- Reduction and subsequent elimination of attitudinal barriers associated with ageism that prevent older adults from living in dignity and accessing resources that have the potential to improve their quality of life

- Establishment and support of an aging-friendly global labor market in which the contributions and competencies of older adults have value and age-related barriers to job recruitment and promotion do not exist

- Development and support of safe and accessible institutional, residential, and commercial environments that are affordable and encourage the involvement of older adults in the cultural life of international communities

- Promotion of full integration of all older adults, including those with physical, psychological, and cognitive disabilities, into programs that support the following objectives: (a) lifelong learning; (b) political participation; (c) intergenerational relationships; (d) cultural, social, and voluntary activities and paid employment introduction; and (e) preservation and strengthening of pension systems that ensure older adults a retirement income that is substantial enough to meet their day-to-day needs and keep them out of poverty

- Development of funding that supports general and mental health treatment and prevention programs that can eliminate sources of physical, psychological, and cognitive disability; substance abuse; and suicidal behavior among older adults and provides access to primary and acute care services as well as rehabilitation technology that can improve their ability to function independently in their communities

- Increased implementation of in-home and facility-based long-term care services to maximize the quality of life and community participation of those older adults with Alzheimer's disease and other cognitive impairments

- Increased development and implementation of respite care programs for family caregivers of all ages on a global scale

- Development and expansion of geriatric education and training programs to increase the number of social workers and other mental health professionals in the field of aging

- Promotion and strengthening of the role that social workers play in meeting the evolving physical and psychosocial needs of older adults through professional practice, policy development, research, and social advocacy. To accomplish these long-term goals, social work professionals will have to develop partnerships with international government agencies and world leaders to advocate for increased funding to support the implementation of effective programs designed to meet the changing needs of world communities that are aging. 


\section{Conclusions and Recommendations}

In sum, the consequences of the rapid pace of global population aging represent a major social crisis that is going to require the coordinated efforts of government organizations around the world to come up with workable policies and programs that can adequately deal with the social challenges of a society that is growing older. In response to these concerns, the United Nations, in collaboration with other international organizations, has put forward a series of recommendations that they believe, if implemented, will successfully be able to mitigate the adverse effects of population aging. Implementation of these recommendations will require the following:

- Reorganization of funding of international social insurance systems in ways that will keep them economically solvent for the security of future generations of older adults

- Changing the way that international social policies related to labor, immigration, and family systems are developed and implemented

- Development of health and wellness initiatives that serve to promote healthy lifestyles in older adult populations on a worldwide basis

- Development of innovative longitudinal research initiatives that will provide policy makers with up-to-date scientific information about the evolving social, economic, and health care service needs of aging adult populations with and without disabilities in international communities

- Development of international cooperation among government officials so that they can share ideas and resources that will allow them to work together to come up with effective solutions that can resolve the socioeconomic and political issues associated with global aging.

\section{References}

Aziz, S. (2002). Summary report of the Second World Assembly on Ageing. Madrid, Spain, April 8-12. Retrieved from www.inpea.net/images/WAA02-meeting-report.pdf

Chappell, N. L., \& Cooke, H. A. (2010). Age-related disabilities: Aging and quality of life. In J. H. Stone \& M. Blouin (Eds.), International encyclopedia of rehabilitation (pp. 1-3). Retrieved from http://sphhp.buffalo.edu/rehabilitation-science/research-and-facilities/funded-researcharchive/center-for-international-rehab-research-info-exchange.html

Davies, E. (2004, August). What are the palliative care needs of older people and how might they be met? Retrieved from http://www.euro.who.int/_data/assets/pdf_file/0006/74688/E83747.pdf

Faiola, A. (2006, July 28). The face of poverty ages in rapidly graying Japan. The Washington Post. Retrieved from http://globalag.igc.org/elderrights/world/2006/japanpoverty.htm

Heilig, G. K., Gerland, P., Andreev, K., Danan Gu, N. L., Spoorenberg, T., Ravinuthala, S., . . . Koshy, N. (2011, May 5). World population prospects, the 2010 revision: Estimation and projection methodology. Retrieved from http://www.gerhard-k-

heilig.com/main/ppt/WPP_2010_Methodology_Rev1.pdf

International Federation of Social Workers (IFSW). (2008) Ageing and older adults. Retrieved from http://ifsw.org/policies/ageing-and-older-adults/ 
International Longevity Center Japan. (n.d.) Aging in Japan. Retrieved from http://www.ilcjapan.org/agingE/

Japan population to shrink by a third by 2060. (2012, January 30). The Guardian. Retrieved from https://www.theguardian.com/world/2012/jan/30/japan-population-shrink-third

Kramarow, E., Lentzner, H., Rooks, R., Weeks, J., \& Saydah, S. (1999) Health and aging chartbook: Health, United States, 1999. Retrieved from https://www.cdc.gov/nchs/data/hus/hus99cht.pdf

Marlow, I. (2017, May 3). Japan's bold steps. The Globe and Mail. Retrieved from https://beta.theglobeandmail.com/globe-investor/retirement/retire-planning/how-japan-iscoping-with-a-rapidly-agingpopulation/article27259703/?ref=http://www.theglobeandmail.com

Ministry of Internal Affairs and Communications Bureau of Statistics. (1996). Japan statistical yearbook, Chapter 2: Population and households. Retrieved www.stat.go.jp/english/data/nenkan/1431-02.htm

Murray, C. J., \& Lopez, A. D. (1997). Alternative projections of mortality and disability by cause 1990-2020: Global burden of disease study. Lancet, 349, 1498-1504.

National Association of Social Workers. (2004). NASW standards for palliative and end of life care. Retrieved from https://www.socialworkers.org/LinkClick.aspx?fileticket=xBMd58VwEhk\%3d\&portalid=0

Office of National Statistics. (1999). Mortality statistics: General: Review of the Register General on deaths in England and Wales, 1997 (Series DH1, No. 30). Retrieved from http://www.worldcat.org/title/mortality-statistics-general-england-wales1997/oclc/247256692\&referer=brief results

United Nations, Department of Economic and Social Affairs, Population Division. (2007). World population prospects: The 2006 revision: Highlights (Working Paper No. ESA/WP.202). Retrieved from http://www.un.org/esa/population/publications/wpp2006/WPP2006_Highlights_rev.pdf

United Nations, Division for Social Policy and Development. (2002). Political declaration and Madrid international plan of action on ageing. Second World Assembly on Ageing, Madrid, Spain April 8-12, Retrieved from http://www.un.org/esa/socdev/documents/ageing/MIPAA/politicaldeclaration-en.pdf

U.S. Department of Health and Human Services, National Institute on Aging, National Institutes of Health, \& U.S. Department of State. (2007, March). Why population aging matters: A global perspective (Publication No. 07-6134). Retrieved from https://www.nia.nih.gov/sites/default/files/2017-06/WPAM.pdf

U.S. Department of Health and Human Services, National Institute on Aging, National Institutes of Health, \& World Health Organization (WHO). (2011, October). Global health and aging (NIH Publication No. 11-7737). Retrieved from http://www.who.int/ageing/publications/global_health.pdf

World Health Organization (WHO). (2004). Better palliative care for older people. Retrieved from http://www.euro.who.int/_data/assets/pdf_file/0009/98235/E82933.pdf

World Health Organization (WHO). (2008). The global burden of disease: 2004 update. Retrieved from http://www.who.int/healthinfo/global_burden_disease/GBD_report_2004update_full.pdf?ua=1 
World Bank. (2008). The economic implications of chronic illness and disability in Eastern Europe and the former Soviet Union. Retrieved from http://documents.worldbank.org/curated/en/351921468030612583/pdf/428510rev10PUB1SE0 ONLY10Feb02702008.pdf

The Journal of Social Work in the Global Community, sponsored by Walden University, is a scholarly peer-reviewed journal that promotes research in the practice of international social work with a focus on social change. JSWGC publishes high-level research, literature and book reviews, and thought pieces related to the field of social work practice and social change in our global community.

Walden University Publishing: http://www.publishing.waldenu.edu 